\title{
UJI KELAIKAN INSTALASI LISTRIK ASRAMA MAHASISWA DI JAKARTA (STUDI KASUS DI ASRAMA MAHASISWA ISLAM SUNAN GUNUNG JATI DAN ASRAMA MAHASISWA ISLAM SUNAN GIRI) \\ ${ }^{1}$ Raja Ingan Budi, ${ }^{2}$ Massus Subekti, ${ }^{3}$ Imam Arif Rahardjo \\ ${ }^{1,2,3}$ PendidikanTeknik Elektro, Fakultas Teknik, Universitas Negeri Jakarta \\ ${ }^{1}$ Email : rajainganbudi@gmail.com
}

\begin{abstract}
The purpose of this research is to discover worthiness of electrical installation in Sunan Gunung Jati Moslem College Student Dormitory and Sunan Giri Moslem College Student Dormitory based on PUIL 2011 standardization.

This research uses qualitative method by using data table and so on analyze based on PUIL 2011 standardization. Data analysis technique used is descriptive analysis. In preview results/observation results the lowest score (No) is 0 , the highest score (Yes) is 1 . These data results used interval as guidance feasibility test of electrical instalation at college student dormitory. The aim of using interval for quantify amount of the lowest score (No) which is obtained. If the lowest score (No) which is obtained more, so the end result is No Operational Worthiness (TLO) but if the highest score (Yes) which is obtained more, so the end result is Operational Worthiness (LLO).

The conclusion of this research is electrical installation properness, component selection of electrical instalation, and utilization of Mini Circuit Breaker are appropiate based on PUIL 2011 standardization. Isolation resistance in Sunan Gunung Jati Moslem College Dormitory is $200 \mathrm{M} \Omega$ and it's quite good. Isolation resistance in Sunan Giri College Dormitory is 1,3 M $\Omega$ and it's fairly good. Both Sunan Gunung Jati Moslem College Student Dormitory and Sunan Giri Moslem College Student Dormitory there is no grounding resistance. To consider about electrical safety factor such as Grounding and PE Conductor Protection. So the end results in Sunan Gunung Jati Moslem College Student Dormitory which is the lowest score (No) that dormitory got is 13 point or No Operational Worthiness (TLO) and Sunan Giri Moslem College Student Dormitory which is the lowest score (No) that dormitory got is 12 point or No Operational Worthiness (TLO). Keywords : Feasibility, Electrical Installation, College Student Dormitory
\end{abstract}

\begin{abstract}
Abstrak
Tujuan penelitian ini yaitu untuk mengetahui kelaikan instalasi listrik Asrama Mahasiswa Islam Sunan Gunung Jati dan Asrama Mahasiswa Islam Sunan Giri berdasarkan standar PUIL 2011.

Penelitian ini menggunakan metode kualitatif dengan menggunakan form tabel pengumpulan data yang selanjutnya dianalisis sesuai dengan standar PUIL 2011. Teknik analisis data yang digunakan yaitu analisis deskriptif. Dalam tabel hasil pengamatan skoring terendah (Tidak) diberi nilai 0, skoring tertinggi (Ya) diberi nilai 1. Pada pengolahan hasil penelitian digunakan rentang interval sebagai acuan status kelaikan asrama mahasiswa tersebut. Penetuan rentang interval ini digunakan untuk mengukur banyaknya skoring terendah (Tidak) yang diperoleh. Jika skoring terendah (Tidak) yang diperoleh banyak maka hasil penelitiannya Tidak Laik Operasi (LLO) namun jika skoring terendah (Tidak) yang diperoleh sedikit dengan kata lain skoring tertinggi (Ya) yang diperoleh banyak maka hasil penelitiannya Langsung Laik Operasi (LLO).

Kesimpulan dari penelitian ini adalah kelengkapan pemasangan dan pemilihan komponen perlengkapan listrik serta pengaman MCB telah sesuai dengan standar PUIL 2011. Tahanan Isolasi pada Asrama Mahasiswa Islam Sunan Gunung Jati Matraman bernilai $200 \mathrm{M} \Omega$ dan tergolong baik sedangkan Tahanan Isolasi pada Asrama Mahasiswa Islam Sunan Giri bernilai 1,3 M $\Omega$ dan tergolong cukup baik. Pada penelitian ini tidak terdapatnya sistem pembumian. Mengingat faktor materi uji keselamatan ketenagalistrikan seperti proteksi sistem tak langung dan proteksi PE tidak terdapat dilapangan. Maka hasil akhir pada penelitian ini adalah pada Asrama Mahasiswa Islam Sunan Gunung Jati Matraman status kelaikannya Tidak Laik Operasi (TLO) dengan banyaknya poin skor terendah (tidak) yang didapatkan 13 poin dan hasil akhir pada Asrama Mahasiswa Islam Sunan Giri Rawamangun status kelaikannya Tidak Laik Operasi (TLO) dengan banyaknya poin skor terendah (tidak) yang didapatkan 12 poin.
\end{abstract}

Kata Kunci : Kelaikan, Instalasi Listrik,Asrama Mahasiswa,PUIL 2011

\section{PENDAHULUAN}

Berdasarkan statistik data kebakaran yang dihimpun oleh Dinas Penanggulangan Kebakaran dan Penyelamatan Provinsi DKI Jakarta dari tahun 2013-2017 bahwa penyebab kebakaran tertinggi disebabkan oleh listrik. Pada tahun 2013 kasus kebakaran tertinggi disebabkan oleh listrik dengan banyaknya 725 kasus, Selanjutnya pada tahun 2014 kasus kebakaran yang disebabkan oleh listrik masih menjadi penyebab tertinggi dengan banyaknya 684 kasus, pada tahun 2015 penyebab tertinggi kebakaran di DKI Jakarta yang disebabkan oleh 
listrik mengalami titik puncaknya dengan banyaknya 828 kasus, kemudian pada tahun 2016 kasus kebakaran yang disebabkan oleh listrik tetap menjadi penyebab utama dengan banyaknya 754 kasus, terakhir pada tahun 2017 penyebab kebakaran terdapat penurunan sedikit dengan banyaknya 704 kasus.(Jakartafire.net/statistic). Kebutuhan energi listrik dalam penggunaannya sangat bermanfaat bagi kehidupan, namun energi listrik memiliki risiko yang sangat besar jika tidak digunakan sesuai standar kelaikan.

Risiko tersebut meliputi manusia, material atau bahan dan metode. Hal itu dapat terjadi dikarenakan listrik memiliki potensi risiko terjadinya hubungan singkat (short circuit) jika terdapat kawat penghantar yang bersentuhan dengan penghantar lain. Oleh karena itu, berdasarkan panduan PUIL 2011 instalasi rumah tinggal dipersyaratkan agar: (1) memiliki kualitas isolasi penghantar yang baik seperti menggunaan besaran kabel yang sesuai agar tidak terjadinya putusnya serat kabel didalamnya, (2) jaringan instalasi listrik juga perlu dibekali dengan proteksi sentuh langsung, proteksi sentuh tak langsung, proteksi terhadap bahaya kebakaran dan Proteksi PE, (3) perlengkapan instalasi listrik yang terpasang juga perlu disesuaikan dengan daya yang terpasang agar tidak terjadi trip /penurunan listrik, (4) Penggunaan pembatas arus atau pengaman instalasi listrik (MCB) juga harus sesuai dengan standar PUIL 2011.

Untuk mengurangi risiko listrik semua instalasi listrik bangunan baru yang telah dipasang instalatir berkualifikasi diharuskan memiliki Sertifikat Laik Operasi (SLO) dari KONSUIL (Komite Nasional Untuk Keselamatan Instalasi Listrik). Hal tersebut dilakukan agar terjaminnya standarisasi instalasi listrik bangunannya. Meskipun demikian tidak semua bangunan memiliki SLO, terutama pada bangunan-bangunan lama yang telah tersambung aliran listrik, dan tentu saja bangunan ini sangat berpotensi terhadap risiko bahaya listrik.

Salah satu bangunan komplek pemukiman di Jakarta adalah asrama mahasiswa yang diperuntukkan bagi sekelompok mahasiswa yang sedang menempuh masa studinya. Sebagian mahasiswa memilih tinggal di asrama dikarenakan keberadaan asrama relatif murah dibandingkan dengan tempat tinggal lainnya. Diantara asrama mahasiswa di Jakarta seperti; Rusunawa UNJ, Asrama Mahasiswa UICCI, Asrama Mahasiswa Islam Sunan Gunung Jati, Asrama Mahasiswa Islam Sunan Giri, Wisma Mahasiswa, dan lain-lain. Pada umumnya asrama mahasiswa di Jakarta telah dilakukan perbaikan fisik. Namun belum tentu jaringan instalasi listrik nya laik sesuai dengan standar PUIL. Berdasarkan paparan tersebut maka perlu dilakukan penelitian untuk mengkaji, apakah instalasi listrik asrama mahasiswa masih laik atau tidak laik

\section{METODE}

Metode penelitian yang digunakan pada penelitian ini adalah metode penelitian kualitatif, dengan menggunakan teknik form tabel pengumpulan data yang selanjutnya dianalisis sesuai dengan standar PUIL 2011. Metode penelitian ini hasil akhirnya berupa kesesuaian atau tidaknya dengan PUIL 2011 instalasi bangunan listrik yang terpasang. Subjek yang diteliti adalah data kualitas meliputi: gambar instalasi, proteksi terhadap bahaya kebakaran, penghantar, polaritas, pemasangan, kelengkapan berstandar SNI, instalasi khusus listrik bangunan, data pengukuran tahanan isolasi dan tahanan pembumian. Pada tabel instrumen penelitian terdapat dua puluh delapan pertanyaan yang terbagi menjadi empat tabel, diantaranya:

1. Tabel Pemeriksaan Gambar Instalasi

2. Tabel Pemeriksaan Proteksi

3. Tabel Pemeriksaan Konduktor

4. Tabel Pengukuran Resistans Insulasi dan Tahanan Pembumian.

Teknik pengumpulan data dalam penelitian ini adalah tabel pengumpulan data serta dokumentasi yang digunakan untuk mengetahui instalasi listrik yang sudah terpasang di asrama mahasiswa tersebut. Dalam pengambilan data ini, peneliti akan mengamati secara langsung objek yang diteliti.

\section{HASIL DAN PEMBAHASAN Hasil}

Pada penelitian ini, peneliti melakukan validitas tabel pengukuran sebagai bahan instrumen penelitian. Validitas intrumen tersebut diterapkan guna mengetahui apakah instrumen tersebut Langsung Laik Operasi, Laik Operasi Catatan Minor, Laik Operasi Catatan Major, atau Tidak Laik Operasi. Instrumen alat ukur dan tabel pengukuran hasil penelitian akan divalidasi oleh KONSUIL. Selanjutnya, setelah instrumen tersebut divalidasi maka penulis akan melanjutkan penelitian di Asrama Mahasiswa Islam Sunan Gunung Jati Matraman dan Asrama 
Mahasiswa Islam Sunan Giri Rawamangun. Dalam penelitian ini objek yang diteliti adalah instalasi listrik pada bangunan pemukiman di Jakarta yaitu Asrama Mahasiswa. Data penelitian tersebut meliputi :

1. Perlengkapan instalasi listrik yang terpasang.

2. Jenis kabel/penghantar yang digunakan pada bangunan instalasi listrik.

3. Jenis pengaman instalasi listrik.

4. Nilai tahanan isolasi pada instalasi listrik.

5. Nilai tahanan pembumian pada instalasi listrik.

\section{- Sakelar}

Pemeriksaan sakelar terdiri dari ketinggian sakelar dari lantai, jenis pemasangan serta merk dagang sakelar. Pada penelitian ini digunakan data responden sebagai penghuni pada ruang kamar di Asrama Mahasiswa. Keterangan Selanjutnya dibawah ini akan dipaparkan penggunaan sakelar di Asrama Mahasiswa.

Pada Asrama Mahasiswa Islam Sunan Giri terdiri atas 16 kamar tidur yang didalamnya terdapat satu sakelar tunggal sedangan pada asrama Mahasiswa Islam Sunan Gunung Jati terdapat 8 Kamar tidur yang didalamnya terdapat satu sakelar tunggal. Pemasangan sakelar yang digunakan yaitu inbow dan outbow. Pada pemasangan outbow sakelar dan dinding diberi pembatas antara sakelar dan dinding dengan kayu yang berfungsi sebagai isolator. Tuas ON/OFF masih berfungsi dengan baik dan masih tertempel kokoh pada dinding. Penempatan sakelar pada ruangan terpasang didekat pintu atau mudah terjangkau dengan ketinggian antara $145-170 \mathrm{~cm}$. Merk dagang yang digunakan yaitu Panasonic,Broco, Clipsal dan ada juga yang tidak memiliki merk dagang.

\section{- Kotak Kontak}

Pemeriksaan kotak kontak terdiri dari ketinggian kotak kontak dari lantai, kabel penghantar yang digunakan, jenis pemasangan dan merk dagang kotak kontak. Pada penelitian ini digunakan data responden sebagai penghuni pada ruang kamar di Asrama Mahasiswa.

Pemeriksaan kotak kontak yang digunakan pada ruang kamar di Asrama Mahasiswa Islam Sunan Giri rawamangun menggunakan kabel netral berwarna biru dan kabel fasa berwarna hitam. Jenis kotak kontak yang digunakan diruang kamar Asrama Mahasiswa Islam Sunan Giri Rawamangun adalah kotak kontak cabang yang tertempel dinding. Sedangkan pada Asrama Mahasiswa Islam Sunan Gunung Jati menggunakan kabel netral berwarna biru dan kabel fasa berwarna hitam. Jenis kotak kontak yang digunakan pada Asrama Mahasiswa Islam Sunan Gunung Jati Matraman adalah inbow. Berdasarkan peraturan PUIL 2011 warna konduktor pada kotak kotak dianjurkan menggunakan kabel hitam untuk fasa, kabel biru untuk netral, dan kabel hijau-kuning untuk grounding Polaritas kabel yang terpasang fasa terletak sebelah kiri, netral sebelah kanan.

\section{- Fitting}

Pemeriksaan fitting terdiri dari ketinggian dari lantai, warna insulasi kabel, polaritas kabel. Pada penelitian ini digunakan data responden sebagai penghuni pada ruang kamar di Asrama Mahasiswa.

\section{- Jenis Penghantar}

Jenis kabel yang digunakan berjenis NYM tertanam dalam dinding dan NYM terpasang dalam pipa PVC. Pemasangan pipa PVC menggunakan klem yang tertempel pada dinding dan langit-langit sebagai penghubung menuju fitting lampu. Penyambungan kabel dilakukan didalam t-dus dan cukup rapih.

Pengukuran luas penampang kabel dilakukan pada kotak kontak menggunakan mikrometer sekrup. Pengukuran ini dilakukan dikarenakan peralatan elektronik mendapatkan energi listriknya melalui kotak kontak. Oleh karena itu, perlu diperhatikan besar penampang kabel yang digunakan. Luas penampang kabel dinyatakan laik jika kabel yang digunakan bernilai minimum $2,5 \mathrm{~mm}^{2}$.

\section{- Jenis Pengaman}

Asrama Mahasiswa Sunan Gunung Jati dan Asrama Mahasiswa Sunan Giri menggunakan pengaman jenis Mini Circuit Breaker (MCB). Penggunaan pengaman MCB dikarenakan lebih mudah digunakan dan mudah dicari dipasar jika terjadi kerusakan MCB nya dibandingkan MCB berjenis Pengaman lebur/sekering yang tidak praktis dalam penggunaan seperti jika sekering putus, harus mengganti dengan yang baru, selain itu pengaman jenis ini sudah tidak diproduksi kembali sehingga jarang digunakan dipasaran. Pengaman MCB yang ditemukan dilokasi 
penelitian memiliki merk dagang yang beragam diantaranya: BBC, Bright-G, Broco, Hager, Merlin Gerin, dan Schneider.

\section{- Nilai Tahanan Isolasi}

Pengukuran tahanan isolasi pada asrama mahasiswa dilakukan saat tidak adanya tegangan listrik. Perlengkapan elektronik, maupun lampu harus dalam keadaan tidak terhubung dengan sumber listrik. Pengukuran dilakukan pada PHB atau Papan Hubung Bagi. Untuk mendapatkan hasil tahanan isolasi maka alat bantu yang digunakan yaitu Megger. Standarisasi tahanan isolasi pada instalasi listrik jika memiliki nilai tahanan sebesar $\geq 1 \mathrm{M} \Omega$. Tegangan uji yang digunakan adalah Tegangan AC (Arus Searah) yaitu $600 \mathrm{~V}$ dan resistansi $1000 \Omega /$ Volt. Jika nilai tahanan isolasi pada instalasi listrik bernilai 0 sampai $\leq 1 \mathrm{M} \Omega$ maka sudah bisa dipastikan kabel isolasi yang digunakan kurang baik dan sudah seharusnya diganti dengan yang lebih baik demi keselamatan pengguna listrik. Berikut hasil pengukuran tahanan isolasi di Asrama Mahasiswa Sunan Gunung Jati Matraman dan Asrama Mahasiswa Sunan Giri Rawamangun.

\section{- Nilai Tahanan Pembumian}

Pengukuran nilai tahanan pembumian pada instalasi listrik dilakukan dengan alat ukur bantu Earth Tester. Nilai tahanan pembumian memiliki standar kelaikan yang baik jika memiliki nilai $\leq 5 \Omega$. Pada penelitian skripsi ini terdapat kendala dalam melakukan pengukuran tahanan pembumian yaitu tidak adanya tanah kosong untuk penancapan tombak bantu. Secara umum Asrama Mahasiswa Sunan Gunung Jati Matraman dan Asrama Mahasiswa Sunan Giri Rawamangun berada dalam kawasan lingkungan padat penduduk. Selain itu, pada penelitian ini tidak ditemukan adanya elektroda pembumian atau besi grounding pada instalasi listrik asrama mahasiswa. Sehingga tidak memungkinkan melakukan pengukuran tahanan pembumian dikarenakan tidak adanya elektroda pembumian pada gedung tersebut saat dilakukan pengamatan dengan saksama dilapangan hanya kabel fasa dan kabel netral yang terhubung ke kWH meter. Hal tersebut dapat terjadi dikarenakan bangunan Asrama Mahasiswa merupakan bangunan tua yang sudah berdiri lebih dari 50 tahun. Selain itu bangunan Asrama
Mahasiswa terbilang tidak cukup tinggi dibandingkan dengan gedung-gedung sekitarnya. Karena secara umum jika terjadi sambaran petir, petir akan mengenai bangunan yang lebih tinggi dibandingkan bangunan yang lebih rendah.

\section{Pembahasan}

Pada penelitian Asrama Mahasiswa Islam Sunan Giri Rawamangun dari 28 item pemeriksaan instalasi listrik terdapat 15 item pemeriksaan yang dinyatakan Ada/Ya, dan 13 item pemeriksaan yang dinyatakan tidak ada. Kemudian pada penelitian di Asrama Mahasiswa islam Sunan Giri dari 28 item pemeriksaan instalasi listrik terdapat 16 item pemeriksaan yang dinyatakan Ada/Ya, dan 13 item pemeriksaan yang dinyatakan tidak ada.

\section{KESIMPULAN DAN SARAN Kesimpulan}

1. Nilai tahanan isolasi di Asrama Mahasiswa Islam Sunan Gunung Jati Matraman adalah $200 \mathrm{M} \Omega$. Nilai tahanan isolasi di Asrama Mahasiswa Islam Sunan Giri Rawamangun adalah 1,3 $\mathrm{M} \Omega$.

2. Tidak terdapat grounding atau elektroda pentanahan dilokasi penelitian baik di Asrama Mahasiswa Islam Sunan Gunung Jati Matraman maupun di Asrama Mahasiswa Islam Sunan Giri Rawamangun.

3. Penampang kabel yang digunakan di Asrama Mahasiswa Islam Sunan Gunung Jati dan Asrama Mahasiswa Islam Sunan Giri adalah NYM dengan ketebalan $2,5 \mathrm{~mm}^{2}$.

4. Pengaman listrik yang digunakan dilokasi penelitian adalah Mini Circuit Breaker. MCB pada kWH meter di Asrama Mahasiswa Islam Sunan Gunung Jati memiliki kapasitas CL 4. MCB pada kWH meter di Asrama Mahasiswa Islam Sunan Giri Rawamangun memiliki kapasitas CL 32

5. Status kelaikan instalasi listrik pada Asrama Mahasiswa Islam Sunan Gunung Jati dan Asrama Mahasiswa Islam Sunan Giri adalah Tidak Laik Operasi (TLO).

\section{Saran}

1. Faktor keselamatan ketenagalistrikan tentunya harus diutamakan dalam pemasangan instalasi listrik. Peneliti menyarankan kepada pihak Asrama 
Mahasiswa Islam Sunan Gunung Jati dan Asrama Mahasiswa Islam Sunan Giri agar dilakukannya perbaikan secara menyeluruh terkait instalasi listriknya. Faktor-faktor yang dimaksud adalah pemasangan proteksi sentuh tak langsung/sistem pembumian dengan jenis TN-C-S serta pemasangan proteksi PE.

2. Peneliti juga menyarankan agar dipasangnya sirkit masuk sebelum ke sirkit cabang. Selain itu, Pembagian arus ke setiap sirkit cabang hendaknya perlu dievaluasi. Berdasarkan temuan dilapangan terdapat besar arus MCB cabang yang terpasang lebih besar dari Kuat Hantar Arus (KHA) yang dipersyaratkan.

3. Kepada warga Asrama Mahasiswa Islam Sunan Gunung Jati Matraman dan warga Asrama Mahasiswa Islam Sunan Gunung Jati Rawamangun dianjurkan agar senantiasa menjaga perlengkapan instalasi listrik yang terpasang. Bila terjadi hujan deras disertai petir dianjurkan untuk mematikan semua peralatan listrik yang terhubung, hal preventif itu dilakukan agar tidak terjadinya sambaran petir baik terhadap peralatan listrik asrama mahasiswa maupun sambaran terhadap warga asrama mahasiswa. Jika terjadi kerusakan pada bagian perlengkapan listrik segera diganti, atau dapat menghubungi biro teknik listrik PLN bila terdapat kerusakan serius dengan call center 112 .

4. Kepada PLN selaku penyalur listrik tunggal Indonesia hendaknya dapat meninjau ulang ijin listrik bangunan tua di Jakarta. Perlu dilakukan inspeksi rutin yang dilakukan dari pihak PLN mengingat sebagian besar asrama mahasiswa di Jakarta adalah bangunan tua.

\section{DAFTAR PUSTAKA}

Harten, P.Van \& E. Setiawan. (1981). Instalasi Listrik Arus Kuat Jilid I. Bandung: Bina Cipta

Hutagalung,A.R. 2011. Analisis Kehandalan Instalasi Listrik 3 Fasa Gedung bertingkat pada Gedung Jurusan Teknik Elektro FT UNJ.[Skripsi]. Jakarta: Fakultas Teknik, Universitas Negeri Jakarta

[KONSUIL]. 2014. Buku Pedoman Verifikasi Hasil Pemeriksaan dan Pengujian Instalasi Pemanfaatan Tenaga Listrik Tegangan Rendah. Jakarta
Lestari,L.B. (2016). Studi Survey Kelaikan Instalasi Listrik Tegangan Rendah Pada Rumah Tinggal Sederhana Dengan Daya 900-2200 VA. [Skripsi]. Jakarta: Fakultas Teknik, Universitas Negeri Jakarta

[Menteri ESDM] Menteri Energi dan Sumber Daya Mineral. (2016). Rencana Usaha Penyediaan Tenaga Listrik PT. Perusahaan Listrik Negara (Persero) Tahun 2016 s.d 2025. Jakarta

Priowirjanto, Gator. Instalasi Listrik Dasar.2013. Jakarta: Direktorat Pendidikan Dasar dan Menengah Kejuruan, Direktorat Jenderal Pendidikan Dasar dan Menengah

SNI 0225:2011. 2011. Persyaratan Umum Instalasi Listrik 2011. Jakarta: BSN.

Sugiarto,Iis. 2014. Analisis Kelayakan Instalasi Listrik 1 Fasa Pada Rumah Tinggal Sederhana. [Skripsi]. Jakarta: Fakultas Teknik,Universitas Negeri Jakarta.

Sugiyono. 2011. Metode Penelitian Kuantitatif, Kualitatif dan $R \& D$. Bandung: Alfabeta.

Susanta, Agustoni, d.k.k. Kiat Hemat Bayar Listrik. 2009 : Griya Kreasi.

Tim Penyusun Kamus Pusat Bahasa. Kamus Besar Bahasa Indonesia. 2002. Jakarta: Balai Pustaka.

Waluyanti, Sri,d.k.k. 2008. Alat Ukur Dan Teknik Pengukuran Jilid 2 Untuk SMK. Jakarta: Direktorat Pembinaan Sekolah Menengah Kejuruan: DEPDIKNAS RI.

---.Statistik Data Kebakaran Berdasarkan Penyebab. http://jakartafire.net/statistic. diakses pada tanggal 15 Februari 2018 pukul 20:56

---.KYORITSU Instruction Manual. Digital Earth Resistance Tester Model 4105 A. Japan: Kyoritsu Electrical Instruments Works, LTD.

---.SANWA Instruction Manual. Insulation Resistance Tester Type DM508S DM1008S PDM508S Insulation Tester. Chiyoda$\mathrm{Ku}$,Tokyo,Japan. Sanwa Electric Instrument Co.,LTD. 